\title{
Development of Hybrid Vehicle Energy Consumption Model for Transportation Applications-Part II: Traction Force-Speed Based Energy Consumption Modeling ${ }^{\dagger}$
}

\author{
Siriorn Pitanuwat ${ }^{1, *}$, Hirofumi Aoki $^{2} \oplus$, Satoru IIzuka ${ }^{1}$ and Takayuki Morikawa ${ }^{1,2}$ \\ 1 Graduate School of Environmental Studies, Nagoya University, Furo-cho, Chikusa-ku, Nagoya 464-8603, \\ Aichi, Japan; s.iizuka@nagoya-u.jp (S.I.); morikawa@nagoya-u.jp (T.M.) \\ 2 Institutes of Innovation for Future Society, Nagoya University, Furo-cho, Chikusa-ku, Nagoya 464-8603, \\ Aichi, Japan; hiro.aoki@nagoya-u.jp \\ * Correspondence: Siriorn.pita@gmail.com; Tel.: +81-80-6905-2271 \\ + Presented at EVS 31\& EVTeC 2018, The 31st International Electric Vehicle Symposium and Exhibition \\ International Electric Vehicle Technology Conference, Kobe, Japan, 30 September-3 October 2018.
}

Received: 18 April 2019; Accepted: 5 May 2019; Published: 9 May 2019

\begin{abstract}
In the transportation sector, the fuel consumption model is a fundamental tool for vehicles' energy consumption and emission analysis. Over the past decades, vehicle-specific power (VSP) has been enormously adopted in a number of studies to estimate vehicles' instantaneous driving power. Then, the relationship between the driving power and fuel consumption is established as a fuel consumption model based on statistical approaches. This study proposes a new methodology to improve the conventional energy consumption modeling methods for hybrid vehicles. The content is organized into a two-paper series. Part I captures the driving power equation development and the coefficient calibration for a specific vehicle model or fleet. Part II focuses on hybrid vehicles' energy consumption modeling, and utilizes the equation obtained in Part I to estimate the driving power. Also, this paper has discovered that driving power is not the only primary factor that influences hybrid vehicles' energy consumption. This study introduces a new approach by applying the fundamental of hybrid powertrain operation to reduce the errors and drawbacks of the conventional modeling methods. This study employs a new driving power estimation equation calibrated for the third generation Toyota Prius from Part I. Then, the Traction Force-Speed Based Fuel Consumption Model (TFS model) is proposed. The combination of these two processes provides a significant improvement in fuel consumption prediction error compared to the conventional VSP prediction method. The absolute maximum error was reduced from $57 \%$ to $23 \%$, and more than $90 \%$ of the predictions fell inside the $95 \%$ confidential interval. These validation results were conducted based on real-world driving data. Furthermore, the results show that the proposed model captures the efficiency variation of the hybrid powertrain well due to the multi-operation mode transition throughout the variation of the driving conditions. This study also provides a supporting analysis indicating that the driving mode transition in hybrid vehicles significantly affects the energy consumption. Thus, it is necessary to consider these unique characteristics to the modeling process.
\end{abstract}

Keywords: Traction Force-Speed Based Fuel Consumption Model (TFS model); vehicle-specific power; hybrid vehicles; vehicle energy consumption modeling; transportation energy 


\section{Introduction}

Dominating around $45 \%$ of the global fuel consumption each year, the transportation sector is one of the primary contributors that emit a tremendous amount of carbon dioxide to the atmosphere [1]. To address the problem, several measures and policies have been enforced. The regulation of tailpipe emissions and fuel consumption is one of the most explicit examples. It forces the penetration of hybrid and electric powertrain vehicles to the market [2]. Thus, the evaluation of the impact of the transition of the powertrain technologies on the environment, fuel consumption, and emission models has become substantial.

Recently, there have been several hybrid powertrain configurations introduced into the market and on the road. A power-split hybrid vehicle is one of the most widespread series-parallel hybrid powertrain configurations [3]. The remarkable concept of this powertrain is that it detaches the speed between the wheels and the engine. Thus, the engine can operate regardless of the driving speed $[4,5]$. The system also takes advantage of the electric motor/generators (MG) which deliver quick response and high efficiency to assist and absorb the engine power. As a result, it allows more flexibility for the engine to operate onto the optimum regions. This configuration also provides multi-power flow paths that are known as multi-operation modes, such as electric drive, hybrid drive with battery charging, hybrid drive with electric motor assist, regenerative braking, and others. Each mode also provides different operation efficiency ranges. To achieve the maximum efficiency of the system, the energy management system (EMS) is a key component. It contains powertrain operation logic that controls and switches the operation mode to satisfy the driving condition and power usage. The EMS of most hybrid vehicles is constructed by a rule-based control algorithm. This algorithm contains a constraint that defines the conditions for the driving mode selections. It generally determines instantaneous wheel driving force at vehicle speed $[4,6]$.

In the past decades, a number of researchers have been applying vehicle fuel consumption models to transportation research such as prediction and analysis. The conventional approach of vehicle fuel consumption modeling consists of two main processes, which are vehicle driving power estimation, and fuel consumption and driving power relationship construction [2,7-15]. In 1999, Jiménez et al. [16] derived an equation for vehicle driving power estimation, and also provided a set of coefficients specified for light-duty vehicles' (LDVs) application called vehicle-specific power (VSP). The equation simply requires data that can be observed from outside of the vehicles, such as speed, acceleration, road grade, and wind speed. Furthermore, a large number of researchers adopting VSP in their research have reported on the monotonically increasing relationship between VSP and fuel consumption [2,7-18].

For hybrid vehicles, the powertrains consist of two propulsion power sources that result in more complexity for the energy consumption modeling process. Also, hybrid vehicles deliver the propulsion power in multi-operation modes. Each mode delivers the output efficiency at different ranges. To capture the energy consumption characteristics of hybrid vehicles, Frey et al. [7] proposed an approach to model fuel consumption and emissions for alternative vehicle technologies. First, the model estimated the vehicles' driving power by using the conventional VSP equation with the coefficients for LDV. The fuel consumption data were binned into 14 discrete VSP ranges. The average fuel consumption rate at each VSP bin was calculated and established as a fuel consumption model. Since then, this method has been adopted by several transportation energy consumption and emission studies, and has become a conventional method among this field. In a related study, Zhai et al. [12] attempted to develop a fuel consumption model for a hybrid vehicle, the Toyota Prius generation 3 (Prius3). The study quantified the engine on/off criteria by setting the maximum power threshold for each speed and acceleration range. Then, the conventional VSP modeling method was employed to construct the fuel consumption and emission models during the engine-on state period.

Duarte et al. [8] applied exactly the same convention VSP equation as a tool to evaluate the effect of the battery state of charge (SOC) on the fuel consumption of the 2011 Toyota Prius. Based on the 14 VSP bin basis, this study classified the data into four different SOC ranges. The results were analyzed based on the time-spent distribution, the average fuel consumption rate, and the average emission 
rate. Graver et al. [15] also applied the same methodology for plug-in hybrid vehicles by using the conventional VSP equation with the coefficients for LDV, but using $1 \mathrm{~kW} /$ ton bin intervals. However, this study classified the data into two groups: engine on and off, instead of SOC. Then, it also took both electricity and fuel energy usage into account instead of fuel consumption.

Holmén and Sentoff [14] utilized the conventional VSP equation with LDV coefficients and the $1-\mathrm{kW}$ VSP binning method to analyze the benefit of hybrid vehicles compared to internal combustion engine vehicles. This study separated the model into three driving scenarios-city, suburban, and highway-in an attempt to investigate the benefit factors for hybrid vehicles' fuel savings at each driving scenario. On the other hand, this research pointed out a significant drawback of the conventional VSP method. It is interesting to note that VSP models constructed from the same vehicle cannot provide similar model outcomes when they experience different traffic or driving conditions. It implied that the conventional VSP fuel consumption modeling that has been adopted in a tremendous number of research studies may lack some key parameters. The driving power might not be the only primary parameter that contributes to vehicles' fuel consumption. Zhou and Jin [13] attempted to improve the fidelity of the conventional VSP binning modeling method by introducing a transient fuel consumption model. This model consisted of two sub-modules: steady-state and transient modules. To classify the transient data, boundaries were fitted to a scattered plot of speed and acceleration data slightly below the rim of the data cloud. Then, the transient model was constructed by fitting a curve on the speed and fuel consumption data at different discretized acceleration levels.

According to the previous literature, an enormous number of studies has actively adopted the conventional energy consumption modeling method. Nevertheless, only a small number of studies have made an attempt to improve the conventional VSP modeling. Applying the VSP equation and the LDV coefficients proposed since 1999 to estimate the driving power of the current vehicle models can cause a significant error to the estimation and the downstream modeling process [19]. Moreover, there were some studies that pointed out that driving power might not be the only primary parameter contributing to vehicles' fuel consumption. Particularly for hybrid vehicles, the powertrain is capable of enabling multi-operation modes that deliver different energy efficiency. Thus, to develop a fuel prediction model for hybrid vehicles, it is necessary to take these unique characters of hybrid vehicles into account. However, there are no researchers or studies addressing this issue in the current literature. Thus, the objectives of this study are:

(1) To investigate and analyze hybrid vehicles' powertrain operation and energy consumption characters in order to suggest further improvement on the conventional VSP energy consumption modeling method.

(2) To organize and develop an energy consumption prediction model that can capture hybrid vehicles' energy consumption characteristics based on the fundamental of the actual hybrid operation, and to extend the application ability of the model to be more captive in various driving conditions.

\section{Experimental Set-Up and Data Acquisition}

\subsection{Analytical Experiment}

This dataset is applied for analysis on hybrid powertrain operation characteristics and the conventional VSP fuel consumption model accuracy. Then, the improvement suggestions are made based on the analysis. For this dataset, an experiment was conducted in the Japan Automotive Research Institute (JARI) at Shirosato Test Center. On-road analytical speed patterns were designed in an attempt to capture the characteristics of the power-split hybrid operation and drivability. The third generation of Toyota Prius (Prius3) was selected as a representative test vehicle. This vehicle contains a series-parallel hybrid powertrain using power-split hybrid configuration. The vehicle has been recognized as one of the most remarkable hybrid vehicle icons. The powertrain system consists of a 1800cc Atkinson cycle engine, MG1, and MG2. The high-voltage battery provides electrical power 
at 201.6 V and 6.5 Ah. The powertrain maximum output power is delivered at $134 \mathrm{hp}$. During the experiment, the vehicle's powertrain operational data, such as engine, MG1, MG2, and battery data, were collected via the on-board diagnostics (OBD) port accessing the Controller Area Network (CAN) from the hybrid control unit. To measure the road grade, wind speed, and vehicle dynamics, an inertia measurement unit with GPS and a Pitot tube wind speed sensor were also installed. The experimental equipment set-up is shown in Figure 1. During the experiment, the driver was assigned to follow the analytical speed patterns, which were maximum acceleration, maximum braking, cruise speed, coast down, constant acceleration/deceleration, free driving, and e-Drive maximum power. These speed patterns were deliberately designed to capture the varieties of powertrain activities and hybrid operation logics, including realistic driving situations. In addition, at the beginning of the trips, the battery's state of charge was controlled to start in between $45-50 \%$. The sample size of this dataset was more than 50,000 data points recording at $8 \mathrm{~Hz}$. The gross vehicles' weight including the driver, two passengers, and equipment was measured on the measurement site and found at $1625 \mathrm{~kg}$.

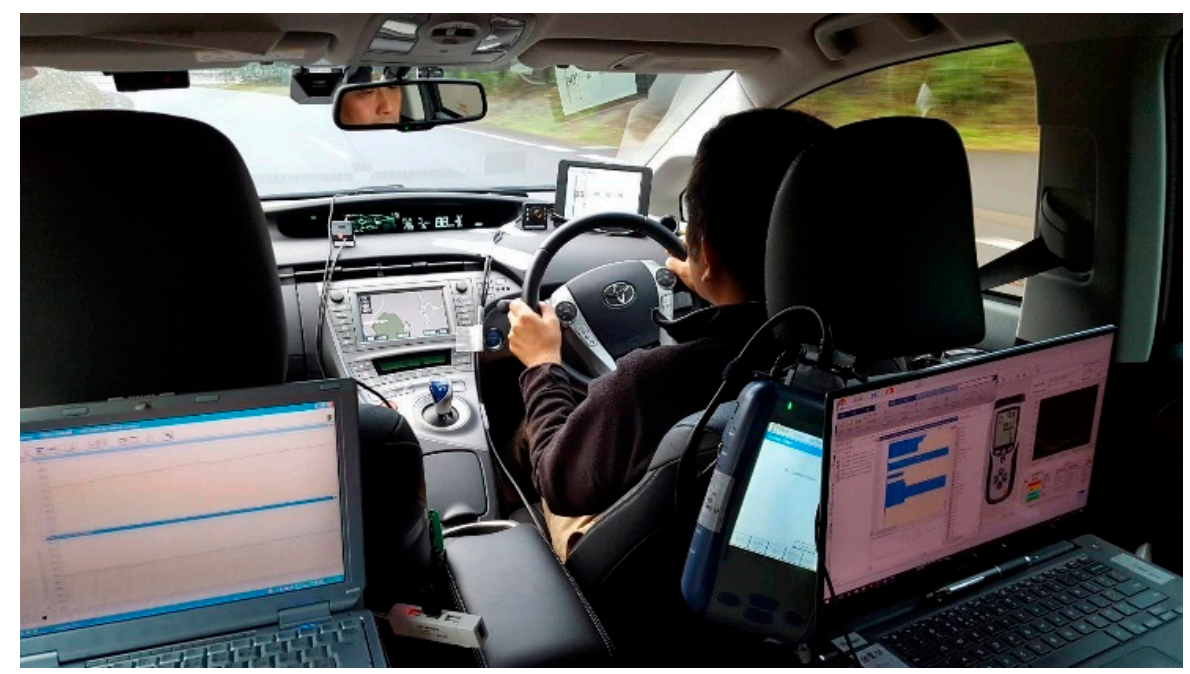

Figure 1. Analytical experimental set-up and equipment.

\subsection{Real-World Experiment}

This dataset is implemented in the fuel consumption model construction and the result validation. This second dataset was collected under real-world traffic conditions in Bangkok, Thailand in 2015. The selected routes were Silom-Sathon Nuea, Rama 3, and Motorway 7, which represented Bangkok's typical city, suburban and highway traffic conditions well, respectively. Figure 2 shows the orientations and locations of the experimental routes. The colors illustrate the population density from high to low as labeled by red, brown, orange, and yellow, respectively. The same Prius 3 model was used as the test vehicle. The CAN data were accessed from the engine control system by the vehicle interface module and Global TechStream software. Vehicle speed, vehicle acceleration, and fuel consumption data were the primary dataset recorded during the experiment. The sampling rate was $1 \mathrm{~Hz}$. This experiment covered more than $400 \mathrm{~km}$ of the OBD data amount with at least three repetitions per route [20]. 


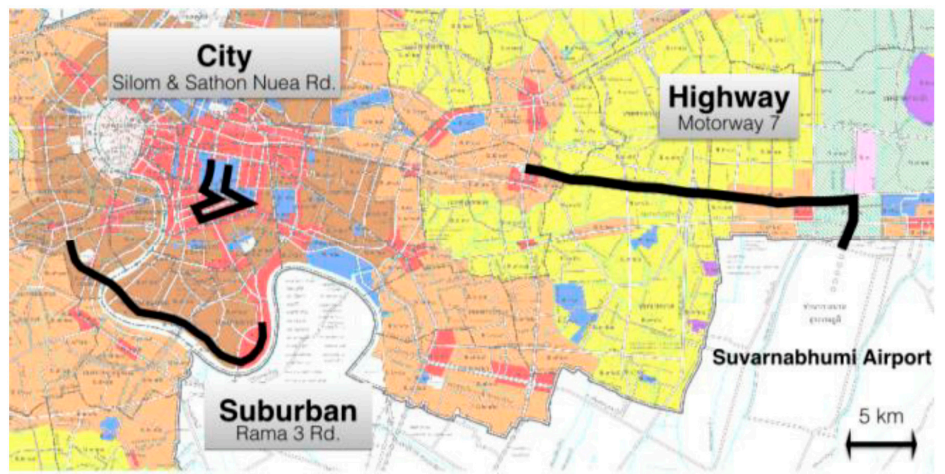

Figure 2. Real-world experiment routes' orientations and locations [20].

\section{Methodology}

\subsection{Investigation of Hybrid Vehicles' Powertrain Operation and Energy Consumption Characteristics}

Power is a function between force and speed. Thus, at one constant power level, it is possible to have multiple pairs of combinations between force and speed data. In general, vehicles operate the powertrain by choosing an optimal operation point that can satisfy the driving force while providing the desired speed. Even though the output power is the same, different force and speed means different powertrain operation points, which result in different energy consumption. Figure 3 shows the insight analysis of the conventional VSP fuel consumption modeling method. This analysis is generated from the analytical experiment dataset. VSP is annotated as the driving power and the color shows the fuel consumption rate at any recorded operation point. This figure attempts to illustrate the fuel consumption variation that occurs at any constant VSP level. From the data, at any layer of a horizon with a constant VSP, the faster the speed, the greater the amount of fuel consumed by the vehicle. Particularly, when the driving power is above $25 \mathrm{~kW}$, the fuel consumption variation becomes more dramatic. This analysis confirms that using only VSP is not sufficient to capture the fuel consumption characteristics of a vehicle since there is still a significant variation of fuel consumption inside a VSP bin.

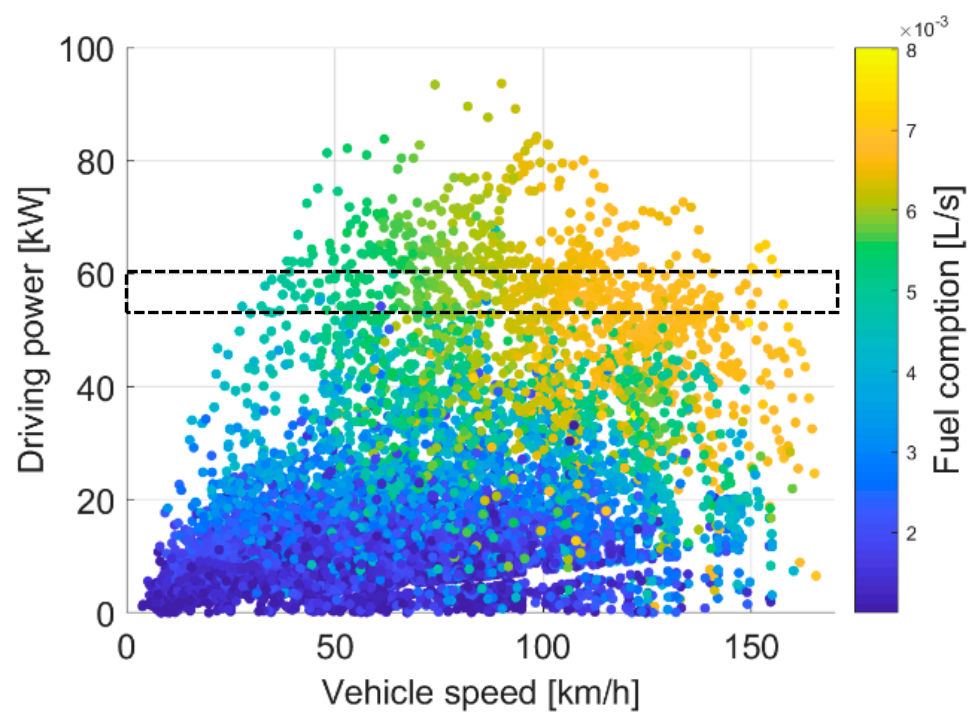

Figure 3. Analysis of the fuel consumption characteristics based on the conventional vehicle-specific power (VSP) fuel consumption modeling method.

In addition, according to the fundamental of the powertrain operation mechanism, the driving force and vehicle speed are the primary factors that are used for vehicle driving demand power calculation, and indicate the target of the powertrain's operation points. Most of the hybrid vehicles 
that are available at the present also use rule-based logic control to determine the hybrid powertrain operation modes. The rule-based control basically selects the driving mode based on the instantaneous driving force and vehicle speed $[4,6]$. Each driving mode also delivers different efficiency depending on the actuated powertrain components and power flow paths. Moreover, according to the analytical experiment data in Figure 4, the analysis supports the statement that the hybrid powertrain operation modes in the Prius 3 are also selected based on the driving force and vehicle speed. This study also believes that the criteria are also applied through all Toyota Hybrid System vehicles. Further information on hybrid vehicles' EMS map identification and measurement procedure will be provided in a separate coming paper.

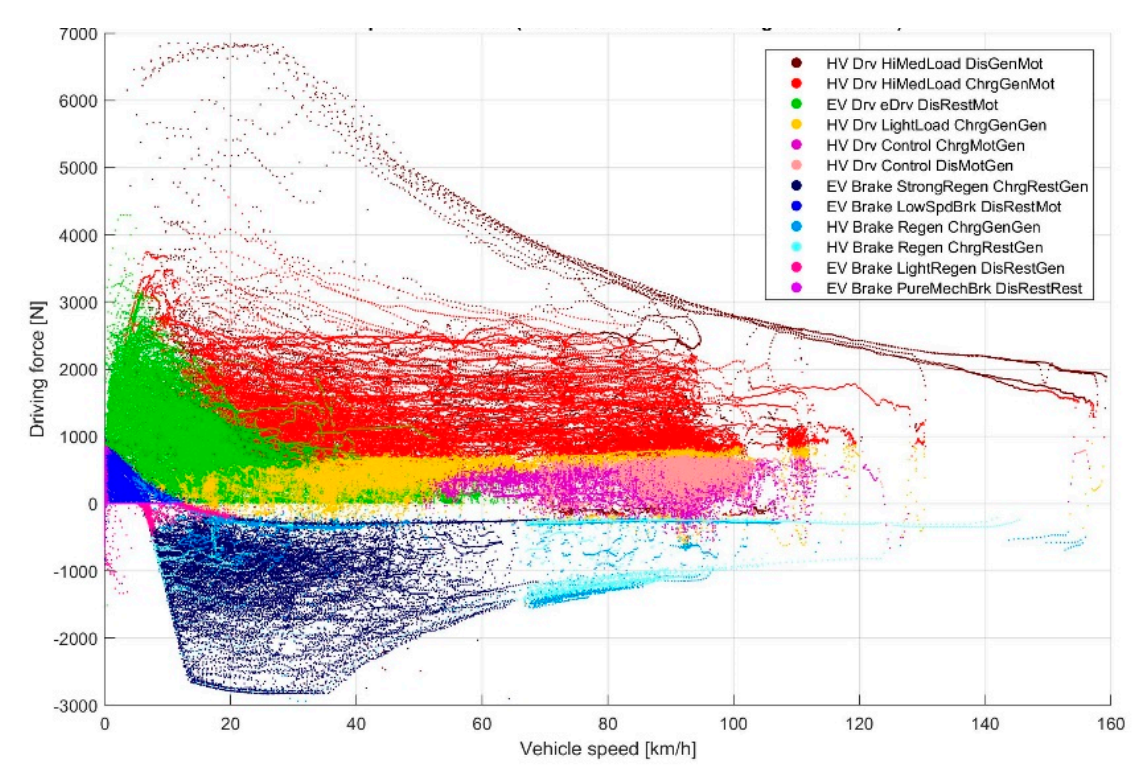

Figure 4. Prius3's hybrid operation mode classification based on instantaneous driving force at wheel and vehicle speed.

Due to the powertrain operation modes being switched mainly based on driving force and speed criteria, it implies that hybrid powertrain fuel consumption and efficiency are suitable to be modeled by driving force and speed rather than by driving power. Thus, this study proposes the Traction Force-Speed Based Fuel Consumption Model (TFS model), which attempts to improve the limitations of the conventional VSP fuel consumption modeling methods. The basic concept of the model construction is designed based on the fundamental of hybrid vehicles' powertrain operation. The construction process of the TFS model can be divided into two main parts. The first part is to estimate the vehicle's driving power and force (traction force). The second part provides the model construction methodology.

\subsection{Driving Power and Driving Force Estimation}

This section introduces a newly developed driving power equation for Prius 3 called DroPw $w_{\text {Prius } 3}$. All the coefficients were deliberately calibrated to be specifically optimal for Prius3's characteristics. The equation for Prius3's driving power estimation is expressed in Equation (1). The equation development and coefficient optimization processes were provided in Part I of these series papers [19].

$$
\begin{gathered}
D r v P w_{\text {Prius } 3}=0.9994\left(m \cdot v_{\text {veh }} \cdot a_{\text {veh }}\right)+ \\
1.1705\left(m g \cdot v_{\text {veh }} \sin \theta+0.2168\left(\rho_{\text {air }} \cdot v_{\text {veh }}\left(v_{\text {veh }}-v_{\text {wind }}\right)^{2}\right)+0.0111\left(m g \cdot v_{\text {veh }} \cos \theta\right),\right.
\end{gathered}
$$

To confirm the estimation fidelity of the new Prius3 driving equation (DroPw $w_{\text {Prius } 3}$ ), Figure 5 illustrates the comparison of Prius3' driving power estimated by two different methods: the 
conventional VSP equation with the LDV coefficients (VSP LDV1999) proposed by Jiménez et al. [16], and $D r v P w_{P r i u s}[$ [19]. In Figure 5, the driving power estimated by the two driving power equations are validated to the driving power calculated by Prius3's powertrain dynamic modeling method, which can be referenced in Part I. Comparing the correlation between VSP LDV1999 to DroPw Prius3, the correlation is improved from 0.77 up to 0.95 . Furthermore, the prediction accuracy of DrvPw Prius 3 was improved by $23 \%$, and it effectively suppressed the driving power prediction discrepancy at high-speed driving compared to VSP LDV1999.

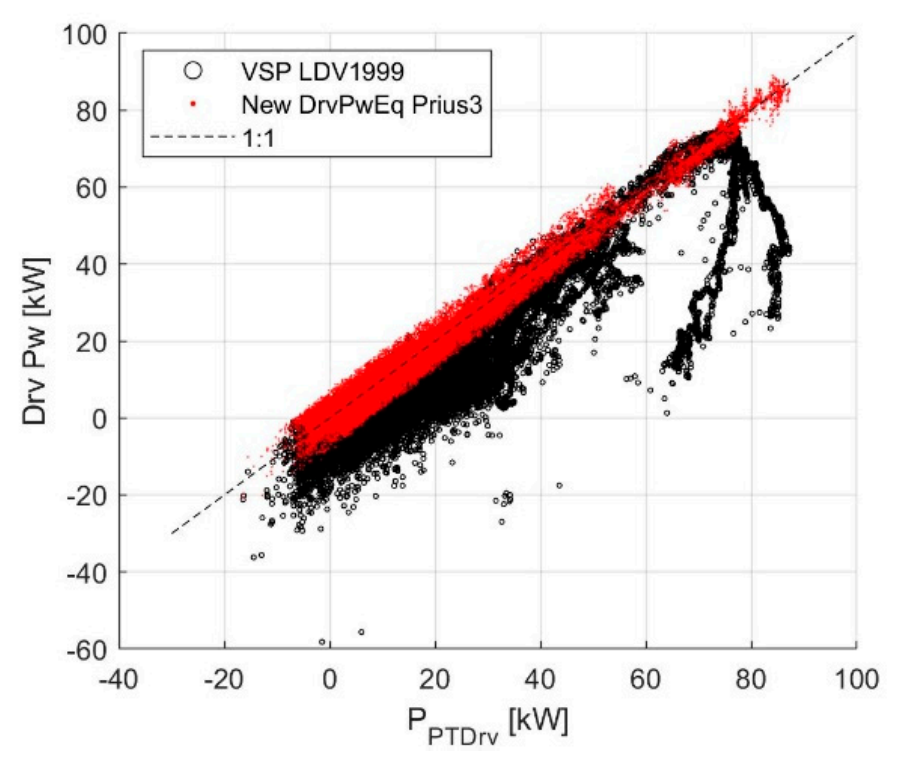

Figure 5. Comparison and validation of Prius3's driving power estimated by two different methods: VSP LDV1999 and DroPw $w_{\text {Prius } 3 .}$

\subsection{Construction of Traction Force-Speed Based Fuel Consumption Model}

The TFS model is intentionally designed according to the fundamental of an actual powertrain's control mechanism and fuel consumption characteristics. First, the driving force and vehicle speed axes are divided into two-dimensional grids. The grid sizes are considered based on the variation of the fuel consumption, the number of data in the grid, and the consistency of the incremental fuel interval of the TFS model. The grid boundaries of the driving force and vehicle speed are set up as specified in Equations (2) and (3).

$$
\begin{gathered}
V_{\text {bound }}=[-100,-0.5: 1: 0.5,20,50: 10: 100,120: 20: 180,200], \\
F_{b o u n d}=[-10000,-5,-0.5,0.5,1,1.5,3,10000],
\end{gathered}
$$

Then, the database, including the vehicle speed, driving force, and fuel consumption, is prepared based on the real-world experiment dataset. Vehicle speed can be obtained from the experiment dataset; however, driving force and fuel consumption need to be calculated. Equation (4) is used to estimate the driving force. It should be cautioned that the average auxiliary load and air conditioning power need to be included into this term before binning. This study inputs $350 \mathrm{~W}$ estimated based on the database. For the fuel consumption, the injection head lift duration signal (Inj) is employed to calculate for the fuel consumption rate. The calculation equation is expressed by:

$$
\operatorname{Fuel}[l / s]=\frac{n \cdot \omega_{i c e} \cdot(\operatorname{Inj} / 10)}{k \cdot 60 \cdot 1000}
$$

where $n$ is the number of cylinders, and $k$ is the number of engine rotations per one injection. For Prius3, $n$ is 4 , and $k$ is 2 . 
Next, the fuel consumption data are binned into the grids, where the specified driving force and vehicle speed range match with the binning data. After this process, the average fuel consumption of all the data in each grid is computed. Then, the complete TFS model is presented in Figure 6. Each line shows the relationship between fuel consumption rate (liter/sec) at different speeds within a specified range of the driving force. The dots on the lines show the average fuel consumption amount that will be used for the prediction. The missing data points indicate the area that the vehicle does not frequently operate. Note that the data analysis and modeling construction conducted in this study were programmed in MATLAB.

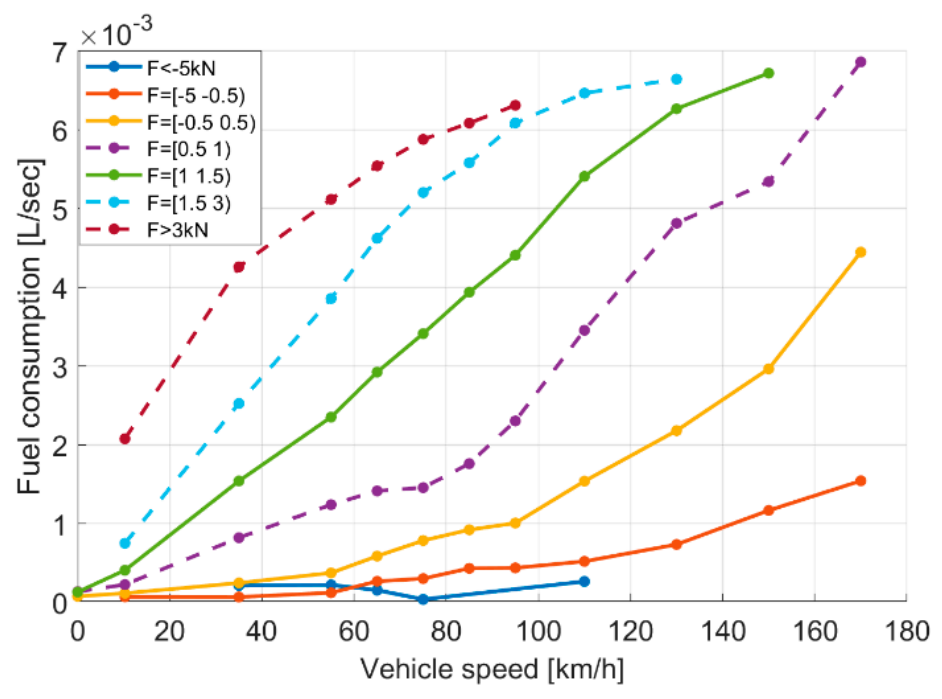

Figure 6. Traction Force-Speed Based Fuel Consumption Model.

\subsection{Model Implementation}

For the model prediction implementation, the requisite input data are the vehicle speed, vehicle acceleration, road grade, wind speed, average auxiliary load, and air conditioning power data. Then, the fuel consumption prediction procedures are explained:

1. Calculate the driving power by using Equation (1); then, sum up with the average auxiliary load and air conditioning power data.

2. Divide the total power by the vehicle speed $(\mathrm{m} / \mathrm{s})$ in order to obtain the driving force.

3. Predict the fuel consumption by using the calculated driving force and speed to find the grid position that is satisfied with the calculated driving force and speed level, and then collect the fuel consumption rate of the grid from TFS model shown in Figure 6. Note that the driving force and speed boundaries were specified in Equations (2) and (3).

4. Multiply the fuel consumption rate with the time interval of the input data, and calculate the total fuel consumption of the overall trip.

\section{Results and Discussions}

Referring to Figure 4, the boundary of the electric vehicle (EV) driving mode (lime green) covers the area up until the maximum speed, which is approximately $64 \mathrm{~km} / \mathrm{h}$. It illustrates the boundary at which the Prius3 switches the driving mode from EV to hybrid vehicle (HV), which is either when the operation point falls outside the EV boundary, or the battery power is insufficient. Projecting these characteristics onto the model in Figure 6, at speeds below $64 \mathrm{~km} / \mathrm{h}$ and when the driving force is lower than $0.5 \mathrm{kN}$, the average fuel consumption is comparatively small compared to the models of the driving force higher than $0.5 \mathrm{kN}$. This also includes the first two modes of the driving force ranges at $0.5-1 \mathrm{kN}, 1-1.5 \mathrm{kN}$, and $1.5-3 \mathrm{kN}$. The overall fuel consumption trend shows that the higher the driving 
force, the more fuel the vehicle consumes. The relationships between the vehicle speed and the fuel consumption rate at different driving force ranges all present fine curve trajectories except for the force range between $0.5-1 \mathrm{~kW}$. The supporting reason is that the data at the driving force between $0.5-1 \mathrm{~kW}$ pass through six different operation modes. Since the power flow path and operation of the engine, MG1 and MG2, are different at each mode, it is possible to cause the fluctuation of the fuel consumption curve. The final TFS map exhibits a significant impact of the hybrid vehicle's operation mode transition on the energy consumption characteristics. Moreover, the proposed grid boundaries $-V_{\text {bound }}$ and $F_{\text {bound }}$, which were carefully divided based on the fuel consumption variation-eventually found that the bands of all the farce ranges appropriately cover all the significant hybrid vehicles' operation mode transitions.

For the validation process of the Prius3's TFS model, the real-world experiment dataset recorded in Bangkok traffic conditions is employed. Figure 7 shows a plot between the prediction results and the measurement average fuel consumption of 24 driving trips from various driving behaviors and traffic conditions in Bangkok. The correlation was found at R-squared at 0.96 , and $92 \%$ of the overall prediction results were aligned inside the $95 \%$ conference interval band.

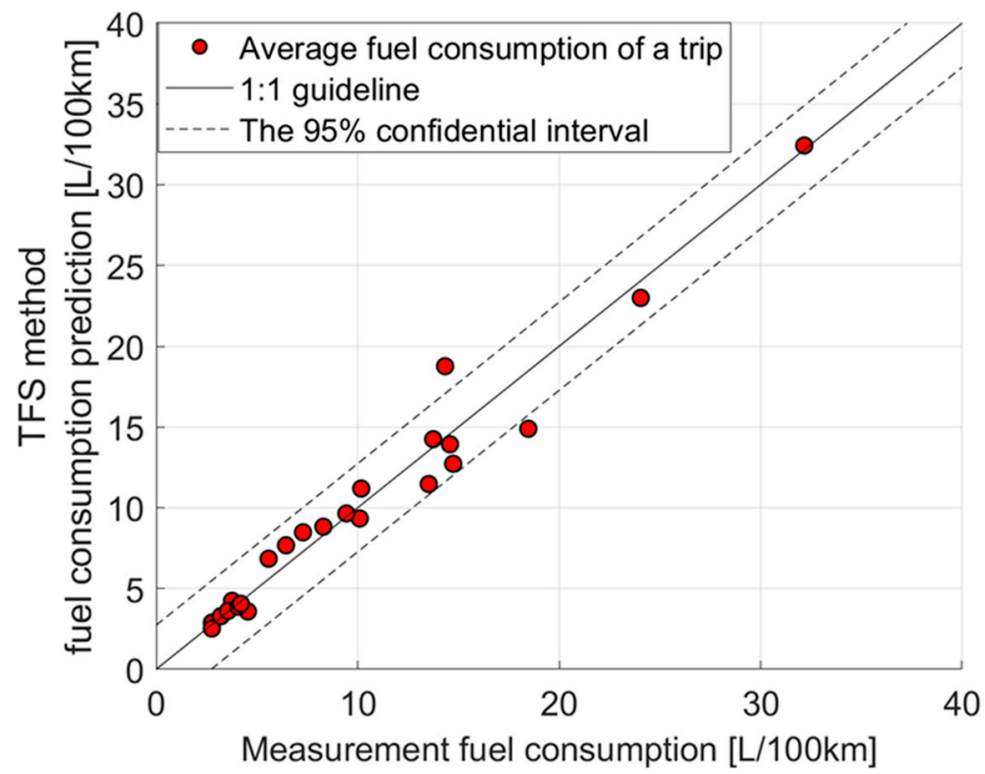

Figure 7. Fuel consumption prediction results of the third generation Toyota Prius (Prius3)'s traction force-speed based model.

Furthermore, this study also investigates the advantages of the new driving power equation combined with the TFS model over combining the conventional VSP equation with the conventional VSP fuel consumption model under real-world driving fuel consumption prediction conditions on the Prius3. Figure 8 shows a comparison of the average fuel consumption among the measurement data and the data from two prediction methods. The red bars illustrate data that were predicted by implementing the new driving power equation model, in order to estimate the instantaneous driving force; then, the driving force was input into TFS model to calculate the fuel consumption (DrvPw $w_{\text {Prius } 3}$ and TFS model). The gray bars illustrate the data that were predicted by the conventional VSP with LDV coefficients to estimate the driving power; then, the fuel consumption results were generated based on the conventional VSP fuel consumption model (VSP LDV1999 and Convt. VSP model). Both methods provide a rational fuel prediction trend from low to high average driving speed compared to the measurement shown in Figure 8. The measurement data show that hybrid vehicles deliver fuel economy from high to low in suburban, highway, and city driving conditions, respectively. The average driving speed between $36-66 \mathrm{~km} / \mathrm{h}$ was prone to be the most optimal driving conditions in terms of the hybrid vehicles' fuel consumption. 


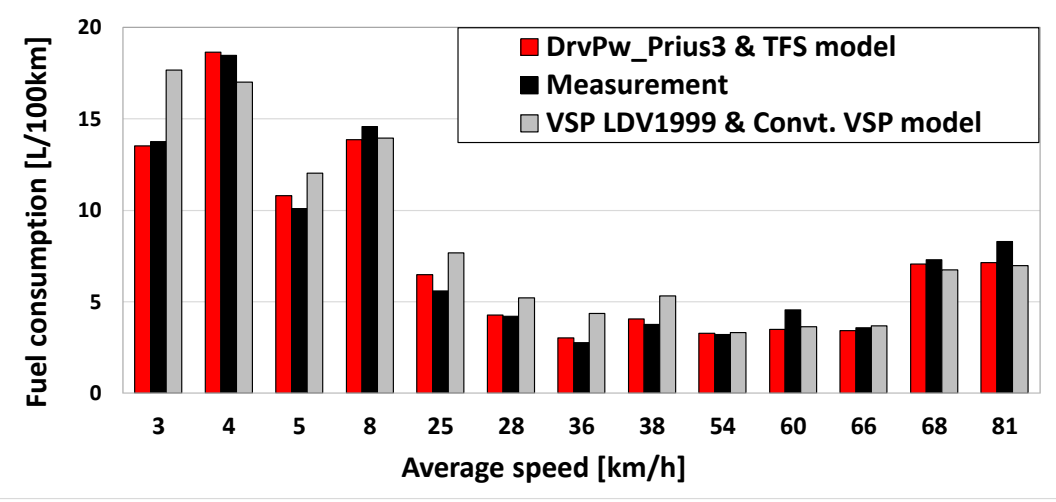

Figure 8. Fuel consumption prediction validation among DrvPw $w_{\text {Prius } 3}$ and TFS model method, measurement data, and VSP LDV1999 and Convt. VSP model method.

Figure 9 shows the error generated by the two comparative methods in various real-world driving conditions in Bangkok from 14 trips of which the average speeds vary from $3 \mathrm{~km} / \mathrm{h}$ to $81 \mathrm{~km} / \mathrm{h}$. From the data, the new method proposed in the study significantly reduces the error from the conventional VSP method. The fluctuation of the fuel consumption prediction is reduced from a range of -20 to $57 \%$ down to -23 to $16 \%$. Particularly, at low to moderate average driving speed, which reflects city and suburban traffic conditions, the conventional VSP fuel consumption model performs an unreliable prediction with the error in a range of -8 to $57 \%$ compared to the measurement. On the other hand, the new method provides much more stability and reliability on the prediction results. It provides sufficient accuracy to capture the complexity of hybrid powertrain fuel consumption characteristics. Moreover, this model is applicable to various driving conditions. Nevertheless, this model requires a larger amount of data than the conventional VSP fuel consumption modeling method. The database used in the model construction should be able to cover a variety of driving incidents.

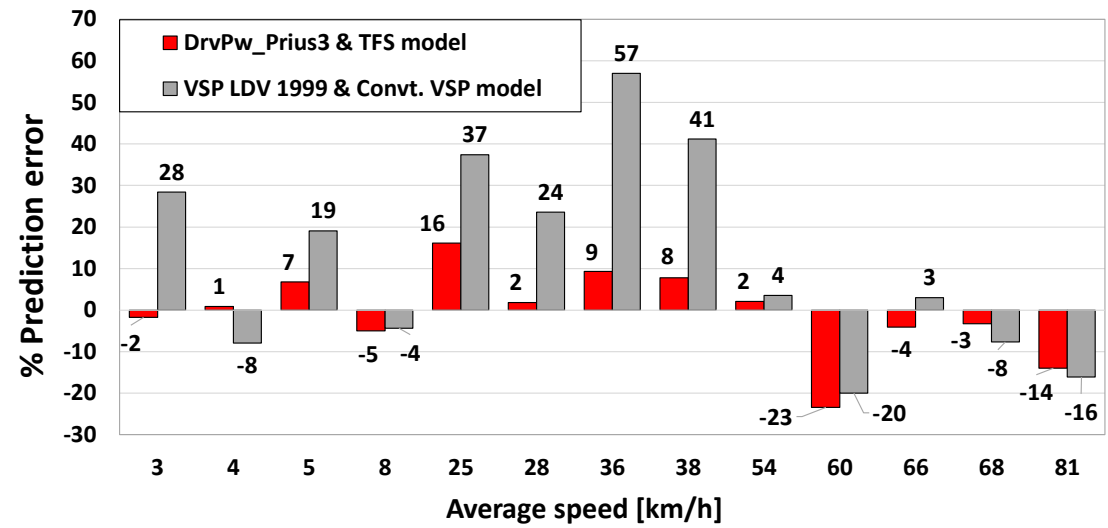

Figure 9. Fuel consumption prediction error between DrvPw $w_{\text {Prius3 }}$ and TFS model method, and VSP LDV1999 and Convt.VSP model method.

\section{Conclusions}

This study proposed a new methodology to model the fuel consumption of a hybrid vehicle based on the fundamental of the powertrain operation mechanism. For the vehicle's driving force estimation, this study applied the new driving power equation with a set of coefficients that was specifically calibrated for the Prius3. The new equation provided accurate estimation at r-squared 0.95.

For the model construction, this study provided a comparative analysis on the fidelity of the conventional VSP fuel consumption modeling method and the fundamental of the hybrid powertrain operation mechanism. This paper discovered that vehicle driving power is not the only primary factor that influences hybrid vehicles' fuel consumption. According to the analysis, this study constructs the 
energy consumption model based on vehicle's driving force and speed called Traction Force-Speed Based Model. The validation results show that this model provided a promising capability on real-world fuel consumption estimation for hybrid vehicles. More than $90 \%$ of the prediction results fell inside the 95\% confidential interval. The Traction Force-Speed Based Model also improved the prediction error from the conventional VSP modeling method from the absolute error at $57 \%$ to $23 \%$ by using the same data acquisition effort. Taking driving force and speed into the model significantly suppressed the fluctuation of the prediction error. Also, it extended the application limitations of the conventional models to be able to capture a variety of driving situations and the impact of hybrid vehicles' operation mode transition on the energy consumption characteristics. In addition, this study has presented evidence that the driving mode transition in hybrid vehicles significantly affects their energy consumption. Thus, it is necessary to consider these unique characteristics to the modeling process.

\section{Further Improvement}

This version of the TFS model is not yet the final version. This model still has not included the electric consumption model of the hybrid vehicle. In addition, the criteria of hybrid vehicles' operation mode switching is primarily determined based on vehicle speed, driving force, and battery SOC. Therefore, the further improvement will also be focusing on battery modeling to predict the real-time SOC and the current operation mode.

Author Contributions: Conceptualization, S.P.; methodology, S.P.; experiment and data acquisition, S.P. and H.A.; data processing, S.P.; data analysis and visualization, S.P.; programming, S.P.; TFS model construction and calculation, S.P.; validation, S.P.; writing — original draft preparation, S.P.; writing-review and editing, S.P.; funding acquisition, H.A.; supervision, H.A., S.I., and T.M.

Funding: This research was funded by Green Mobility Research Institute (GREMO), Nagoya University.

Acknowledgments: In this study, the analytical experiment was supported by Nihon Michelin Tire, Co., Ltd. and the Green Mobility Research Institute (GREMO), Nagoya University. The real-world experiment was supported by the Special Task Force for Activating Research (STAR).

Conflicts of Interest: The authors declare that there is no conflict of interest regarding the publication of this article.

\section{Nomenclature}

$\begin{array}{lll}\text { Symbol } & \text { Description } & \text { Units } \\ m & \text { Gross vehicle mass } & (\mathrm{kg}) \\ g & \text { Gravitational acceleration } & \left(\mathrm{m} / \mathrm{s}^{2}\right) \\ v_{\text {veh }} & \text { Vehicle speed } & (\mathrm{m} / \mathrm{s}) \\ v_{\text {wind }} & \text { Relative wind speed } & (\mathrm{m} / \mathrm{s}) \\ a_{\text {veh }} & \text { Vehicle acceleration } & \left(\mathrm{m} / \mathrm{s}^{2}\right) \\ \theta & \text { Road grade slope } & (\mathrm{rad}) \\ \rho_{\text {air }} & \text { Air density } & \left(\mathrm{kg} / \mathrm{m}^{3}\right) \\ C_{\text {drag }} & \text { Aerodynamic drag coefficient } & - \\ \omega_{\text {ice }} & \text { Engine revolution } & (\mathrm{rad} / \mathrm{s}) \\ \mathrm{n} & \text { Number of engine cylinders } & - \\ \mathrm{k} & \text { Number of engine strokes per one injection } & - \\ \text { Inj } & \text { Injection head lifting duration } & (10 \mathrm{~s}) \\ \text { DrvPw } & \text { The fuel consumption model constructed based on the newly } & - \\ & \text { developed driving power equation for Prius3 and TFS method } & \\ \text { VSPLDV1999 and } & \text { The fuel consumption model constructed based on the conventional } \\ \text { Convt.VSPmodel } & \text { vehicle specific power (VSP) equation with the light duty vehicle } & -\end{array}$




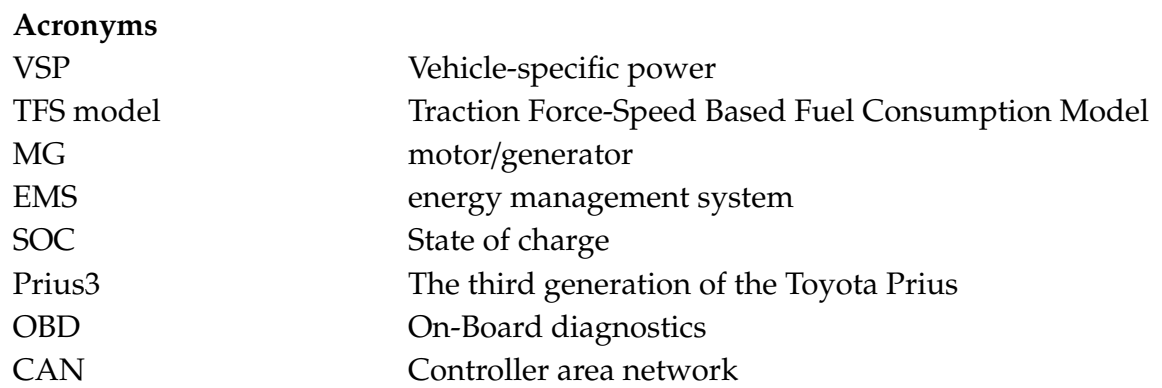

\section{References}

1. Organization of the Petroleum Exporting Countries. 2017 OPEC World Oil Out-Look; Organization of the Petroleum Exporting Countries: Riyadh, Saudi Arabia, 2017.

2. Duarte, G.O.; Gonçalves, G.A.; Farias, T.L. Analysis of Fuel Consumption and Pollutant Emissions of Regulated and Alternative Driving Cycles Based on Real-World Measurements. Transp. Res. Part D Transp. Environ. 2016, 44, 43-54. [CrossRef]

3. Toyota Global Newsroom Toyota Motor Corporation Official Global Website. Available online: https: //global.toyota/en/newsroom/toyota/ (accessed on 3 March 2019).

4. Liu, J.; Peng, H. Modeling and Control of a Power-Split. Control 2008, 16, 1242-1251. [CrossRef]

5. Murphey, Y.L.; Park, J.; Chen, Z.; Kuang, M.L.; Masrur, M.A.; Phillips, A.M. Intelligent Hybrid Vehicle Power Control Part I: Machine Learning of Optimal Vehicle Power. IEEE Trans. Veh. Technol. 2012, 61, 3519-3530. [CrossRef]

6. Sciarretta, A.; Serrao, L.; Dewangan, P.C.; Tona, P.; Bergshoeff, E.N.D.; Bordons, C.; Charmpa, L.; Elbert, P.; Eriksson, L.; Hofman, T.; et al. A Control Benchmark on the Energy Management of a Plug-in Hybrid Electric Vehicle. Control Eng. Pract. 2014, 29, 287-298. [CrossRef]

7. Frey, H.C.; Zhai, H.; Rouphail, N.M. Regional On-Road Vehicle Running Emissions Modeling and Evaluation for Conventional and Alternative Vehicle Technologies. Environ. Sci. Technol. 2009, 43, 8449-8455. [CrossRef] [PubMed]

8. Duarte, G.O.; Varella, R.A.; Gonçalves, G.A.; Farias, T.L. Effect of Battery State of Charge on Fuel Use and Pollutant Emissions of a Full Hybrid Electric Light Duty Vehicle. J. Power Sources 2014, 246, 377-386. [CrossRef]

9. Song, G.; Yu, L.; Tu, Z. Distribution Characteristics of Vehicle-Specific Power on Urban Restricted-Access Roadways. J. Transp. Eng. 2012, 138, 202-209. [CrossRef]

10. Song, G.; Yu, L.; Wu, Y. Development of Speed Correction Factors Based on Speed-Specific Distributions of Vehicle Specific Power for Urban Restricted-Access Roadways. J. Transp. Eng. 2016, 142, 04016001. [CrossRef]

11. Wang, J.; Rakha, H.A. Modeling Fuel Consumption of Hybrid Electric Buses: Model Development and Comparison with Conventional Buses. Transp. Res. Rec. J. Transp. Res. Board 2016, 2539, 94-102. [CrossRef]

12. Zhai, H.; Christopher Frey, H.; Rouphail, N.M. Development of a Modal Emissions Model for a Hybrid Electric Vehicle. Transp. Res. Part D Transp. Environ. 2011, 16, 444-450. [CrossRef]

13. Zhou, M.; Jin, H. Development of a Transient Fuel Consumption Model. Transp. Res. Part D Transp. Environ. 2017, 51, 82-93. [CrossRef]

14. Holmén, B.A.; Sentoff, K.M. Hybrid-Electric Passenger Car Carbon Dioxide and Fuel Consumption Benefits Based on Real-World Driving. Environ. Sci. Technol. 2015, 49, 10199-10208. [CrossRef] [PubMed]

15. Graver, B.M.; Frey, H.C.; Choi, H.-W. In-Use Measurement of Activity, Energy Use, and Emissions of a Plug-in Hybrid Electric Vehicle. Environ. Sci. Technol. 2011, 45, 9044-9051. [CrossRef] [PubMed]

16. Jiménez, J.L.; Mcclintock, P.; Nelson, D.D.; Zahniser, M.S. Vehicle Specific Power: A Useful Parameter for Remote Sensing and Emission Studies Effect of Driving Conditions on Emissions Driving Conditions May Strongly Influence Emissions. In Proceedings of the Ninth CRC On-Road Vehicle Emissions Workshop, San Diego, CA, USA, 19-21 April 1999.

17. Wu, Y.; Song, G.; Yu, L. Sensitive Analysis of Emission Rates in MOVES for Developing Site-Specific Emission Database. Transp. Res. Part D Transp. Environ. 2014, 32, 193-206. [CrossRef] 
18. Duarte, G.O.; Gonçalves, G.A.; Farias, T.L. A Methodology to Estimate Real-World Vehicle Fuel Use and Emissions Based on Certification Cycle Data. Procedia Soc. Behav. Sci. 2014, 111, 702-710. [CrossRef]

19. Pitanuwat, S.; Aoki, H.; Morikawa, T.; Iizuka, S. Development of Hybrid Vehicle Energy Consumption Model for Transportation Application-Part I: Driving Power Equation Development and the Coefficient Calibration. Prep. Process. 2019. submitted.

20. Pitanuwat, S.; Sripakagorn, A. An Investigation of Fuel Economy Potential of Hybrid Vehicles under Real-World Driving Conditions in Bangkok; Elsevier: Bangkok, Thailand, 2015; Volume 79. [CrossRef]

(C) 2019 by the authors. Licensee MDPI, Basel, Switzerland. This article is an open access article distributed under the terms and conditions of the Creative Commons Attribution (CC BY) license (http://creativecommons.org/licenses/by/4.0/). 